\title{
Nitrogen-doped Graphene Modified Glassy Carbon Electrode for Anodic Stripping Voltammetric Detection of Lead Ion
}

\author{
Zuorui Wen ${ }^{l}$, Xueliang Niu ${ }^{l}$, Lijun Yan $^{l}$, Yanyan Niu ${ }^{l}$, Dan Wang ${ }^{l}$, Wei Sun ${ }^{1, *}$, Zaifeng Shi ${ }^{1}$, \\ Lifeng Dong ${ }^{2, *}$ \\ ${ }^{1}$ College of Chemistry and Chemical Engineering, Key Laboratory of Water Pollution Treatment and \\ Resource Reuse of Hainan Province, Hainan Normal University, Haikou 571158, P R China \\ ${ }^{2}$ Department of Physics, Hamline University, St. Paul, MN 55104, USA \\ *E-mail: swyy26@ hotmail.com and donglifeng@qust.edu.cn
}

doi: $10.20964 / 2016.08 .23$

Received: 11 March 2016 / Accepted: 22 May 2016 / Published: 7 July 2016

Nitrogen-doped (NG) graphene modified glassy carbon electrode was prepared for sensitive electrochemical investigation on lead ion $\left(\mathrm{Pb}^{2+}\right)$ with differential pulse anodic stripping voltammetry. Due to the large surface area, excellent conductivity and good adsorption ability of NG nanosheet, $\mathrm{Pb}^{2+}$ can be accumulated and detected with enhanced voltammetric response in the concentration range from $9.0 \times 10^{-9} \mathrm{~mol} / \mathrm{L}$ to $9.0 \times 10^{-5} \mathrm{~mol} / \mathrm{L}$. The detection limit was calculated as $1.91 \times 10^{-9} \mathrm{~mol} / \mathrm{L}$ and the proposed method was applied to fish powder sample determination.

Keywords: Nitrogen-doped graphene; Glassy carbon electrode; Differential pulse anodic stripping voltammetry; Lead ion

\section{FULLTEXT}

(C) 2016 The Authors. Published by ESG (www.electrochemsci.org). This article is an open access article distributed under the terms and conditions of the Creative Commons Attribution license (http://creativecommons.org/licenses/by/4.0/). 